\title{
Delitos Sexuales y Práctica Judicial en Colombia: 1870-1900. Los Casos DE Bolf́far, Antioquia y Santander ${ }^{1}$
}

\author{
Sex Crimes and Judicial Practice in Colombia: 1870-1900. Cases of Bolivar, \\ ANTIOQUIA AND SANTANDER.
}

*JOSÉ WILSON MÁRQUEZ ESTRADA

Historiador de la Universidad Nacional de Colombia. Abogado de la Corporación Universitaria de la Costa. Magister en Historia de la Universidad Nacional de Colombia. Profesor Asistente del Programa de Historia de la Facultad de Ciencias Humanas de la Universidad de Cartagena. Miembro del Grupo de Investigación Frontera, Sociedad y Cultura del Caribe y América Latina (Categoría A1 en Colciencias). Emails: jmarqueze@unicartagena. edu.co, wilsonmarquez99@ yahoo.com.mx

Artículo de Reflexión según clasificación de Colciencias.

1. Artículo producto de una investigación sobre Historia del Derecho en el Caribe Colombiano en el Siglo XIX, que adelantó el autor en el grupo de investigación Frontera, Sociedad y Cultura del Caribe y América Latina (Categoría A1 en Colciencias), del Programa de Historia de la Facultad de Ciencias Humanas de la Universidad de Cartagena.
Por: José Wilson Márquez Estrada*

Artículo Recibido: 14 de junio 2012. Artículo Aprobado: 30 marzo 2013.

\section{RESUMEN}

Este artículo analiza el fenómeno de las conductas agresivas contra la libertad sexual de la mujer a finales del siglo XIX en Colombia, tipificadas como delitos sexuales, y la forma en que se desarrollaban los procesos judiciales con relación a este tipo de criminalidad. Primero se hace un análisis del concepto de delito sexual y de sus diferentes manifestaciones en la sociedad de finales del siglo XIX colombiano, soportado en el estudio de las tipificaciones de dichos delitos en los códigos penales de la época. Luego se hace un estudio de las características de la práctica judicial y del proceso penal en este tipo de delitos, sobre todo de su relación con la mentalidad religiosa y moral de la época. Después se presentan diferentes casos de agresiones sexuales a finales del siglo XIX, específicamente en Antioquia y Santander. Finalmente se hace una presentación de los informes de las autoridades del Estado Soberano de Bolívar sobre la comisión de delitos sexuales en su territorio.

Palabras clave: Delito sexual, Código penal, Control social, Mentalidad religiosa, Peritazgo, Género, Sexualidad.

\section{ABSTRACT}

This article analyzes the phenomenon of aggressive behaviors against sexual freedom of women in late nineteenth-century in Colombia, classified as sexual offenses, and how they developed the legal proceedings regarding this type of crime. First we analyze the concept of sexual crime and its various manifestations in the Colombian society in the late nineteenth century, supported by the study of the criminalization of these offenses in the criminal codes of that time. Then we study the characteristics of judicial practices and criminal procedures in this type of crime, especially its relation to moral and religious mentality of that time. Then there are different cases of sexual assault in the late nineteenth century, specifically in Antioquia and Santander. Finally we study some reports of the authorities of the Sovereign State of Bolivar on the commission of sexual offenses in their territory.

Key words: Sexual offense, penal code, social control, religious mentality, expert advice, Gender, Sexuality. 


\section{INTRODUCCIÓN}

La doctrina cristiana recurrentemente y a través de sus teólogos señalaron a la mujer, como la principal incitadora del pecado en el hombre. Fundamentados en este enfoque, todas las mujeres serían por principio sospechosas, sea cual fuere la conducta del hombre frente a ellas, de provocadoras sexuales y por consiguiente responsables de dichas conductas, quedando el hombre libre de responsabilidad (Bidegain, 1995:154). Al respecto, la historiadora Blanca Melo González señala que:

Las mujeres son sospechosas de incitar, de mentir acerca de su consentimiento, incluso de inventar un ataque no cierto con finalidades escondidas como tapar un "desliz", porque están embarazadas o son histéricas. Pero no sólo las mujeres adultas, también eran sospechosas las niñas. (1999: 116)

La mentalidad patriarcal codifica la sexualidad femenina como seductora y tramposa, suscitadora de los apetitos sexuales viriles, objeto para el desahogo y propiciadora del placer del varón, destinada al dolor y al sufrimiento como castigo y penitencia por su ser y hacer sexual. Con relación a los agresores sexuales, el patriarcalismo falocrático, en su religiosa determinación del sexo de la mujer únicamente por su función reproductiva, mitifica el coito hasta el extremo dejando como inocentes a violadores y abusadores. Aunque la ley permitiera la denuncia y el proceso continuara aún por largo tiempo, la impunidad estaba culturalmente asegurada (Romero, 1998:33). Toda esta visión estaba soportada en la doctrina católica, donde la mujer era el símbolo de la tentación y del pecado. En este panorama cultural la mujer es ubicada en el tejido de relaciones socio-sexuales de conflicto bipolar, jerárquico y de dominio, como objeto y por debajo de la figura del varón, que es asimilado como sujeto, en una clara posición de dominio/subordinación. Entonces, en esta perspectiva, se presenta al varón como el tentado y a la mujer como la tentación que alimenta un imaginario marcado por el desprecio por lo femenino, lleno de varones agresores sin culpa alguna y de mujeres como victimas culpables (Ibíd.: 12).

En el contexto de la cultura colombiana de finales del siglo XIX y con relación a los procesos por agresiones sexuales, las mujeres mayores e incluso las niñas mayores de doce años, siempre son sospechosas de haber consentido los actos y sólo sí hay heridas o contusiones en diferentes partes del cuerpo 
y no sólo el desfloramiento, el proceso investigativo se inicia (Melo, op.cit.: 120). Luego un dictamen médico pericial, cuyo centro de operaciones es el cuerpo de la mujer, corroborará las pruebas iniciales. Para algunos de estos funcionarios judiciales pareciera que el hecho que una mujer llegara a la pubertad significaba la imposibilidad de que se pudiera negar a una "solicitud" de tipo sexual.

El propósito del presente artículo es mostrar las características de la práctica judicial y del proceso penal en materia de delitos sexuales cometidos contra la mujer a finales del siglo XIX en Colombia. El texto está dividido en cuatro partes, en la primera se realiza una aproximación al concepto de delito sexual, en la segunda parte se estudia la tipificación del delito sexual en las codificaciones penales del siglo XIX en Colombia. En la tercera parte se hace un análisis de la práctica judicial en materia de delitos sexuales a finales del siglo XIX en Colombia. En la cuarta parte se presentan diferentes casos de agresiones sexuales a finales del siglo XIX, específicamente en Antioquia y Santander, igualmente se presentan los informes de las autoridades del Estado Soberano de Bolívar sobre delitos sexuales. Para concluir, el texto se cierra con unas consideraciones finales.

\section{DELITOS SEXUALES}

Es interesante analizar, desde la perspectiva del derecho penal contemporáneo en Colombia, qué se entiende por delito sexual, para comprender de qué manera ha evolucionado este concepto desde el siglo XIX hasta hoy. Bajo esta óptica diríamos hoy que delito sexual es aquella expresión generalmente empleada para referirse a acciones que afectan a personas de cualquier edad y sexo, contra su consentimiento y que perturban su desarrollo sexual. Son conductas reprobadas socialmente y legalmente consideradas como delitos contra la libertad y el normal desarrollo psicosexual, que comprenden actos físicos de contenido sexual que se cometen contra una persona de cualquier edad o sexo sin su consentimiento (Bohórquez, 2006: 127). Se denominará "delitos contra la libertad sexual y la dignidad humana". Por consiguiente, los bienes jurídicos tutelados son la libertad y la dignidad humana. En cuanto al primero, es decir, la libertad sexual que no es otra cosa que la facultad y el derecho que tiene toda persona para elegir, rechazar, aceptar y autodeterminar el comportamiento sexual, cuyos límites serán los postulados éticos en que se funda la comunidad y el respeto de los derechos ajenos correlativos. En otras palabras, la libertad sexual es la facultad que tiene la persona para auto 
determinar y auto regular su vida sexual. Así, los delitos sexuales vulneran el derecho de la persona de disponer de su propio cuerpo y, por lo mismo, su objeto de protección se determina en las acciones o fines sexuales verificados mediante la fuerza, abuso, error y engaño ${ }^{3}$

En el siglo XIX colombiano, estos delitos eran considerados por los legisladores como corrompedores de la moral pública y las buenas costumbres, a la vez que introducen en el seno de la familia la perturbación y la desconfianza. Por esta circunstancia esos delitos no se castigan sino cuando se hacen públicos, produciendo escándalo y pasan desapercibidos, por respeto al pudor y al honor de la familia, cuando se ejecutan en secreto, sin que haya nadie que reclame contra ellos (Putnam, 1896: 325). Las conductas más comúnmente tipificadas como delitos sexuales en el siglo XIX en Colombia, según el Código Penal de 1837, los códigos penales del los Estados soberanos y el Código Penal de 1890, fueron: abusos deshonestos, adulterio, fuerza y violencia, estupro, rapto, incesto y sodomía. Todos ellos considerados como ofendedores del pudor y las buenas costumbres. Es necesario resaltar que estos códigos no utilizaban la palabra sexual, pero si son recurrentes en la utilización de la palabra moral (Rodríguez, 1927). Delitos considerados desde la perspectiva de género, ya que el derecho penal del siglo XIX lejos de proteger los intereses de la mujer, contribuyó a asignar y reproducir una determinada significación del ser social mujer, es decir, de la estructura de género. La idea de género viene a expresar que en tanto el sexo está determinado biológicamente, el género se dota de contenido socialmente. Como es regla en la vida social de muchos países, ha sido el hombre el que ha fijado el alcance y la intensidad de la protección penal de la mujer, y no lo ha hecho tanto en función de los intereses femeninos como en función de los estrictamente masculinos en cuanto indirectamente pueden ser supuestamente lesionados por la conducta de la mujer (Martínez, 2000: 83). Para finales del siglo XIX en Colombia, estos delitos conservan aún una fuerte connotación religiosa heredada de la Colonia, por lo que son considerados como conductas desviadas o trasgresiones, que rompen con el "orden natural" de la obra de Dios. Ya que muchas de ellas no están dirigidas al único objetivo de la vida sexual, es decir a la procreación, por lo que son consideradas como actos "contra natura", que deshacen la asociación entre el hombre y Dios, y que "explícitamente se refieren al desperdicio voluntario de la semilla" (Malagón, 2011:18). En esta perspectiva y con relación a la comisión de estos delitos, los informes de los funcionarios judiciales están cargados de prejuicios morales que de alguna manera vician el procedimiento judicial y contaminan la prueba que se pretende constituir.

Sentencia 18455 de Septiembre 7 de 2005-Corte Suprema de Justicia-Sala de 


\section{TIPIFICACIÓN}

El Código Penal del Estado Soberano de Bolívar, fundamentado en el código penal de 1837 y cuyo proyecto de ley fue publicado en la Gaceta de Bolívar que luego fue sancionado en 1872, tipificaba de la siguiente manera los delitos sexuales:

CÓDIGO DE PROCEDIMIENTO EN LOS NEGOCIOS CRIMINALES DEL ESTADO SOBERANO DE BOLÍVAR. CAPITULO 69 DE LOS RAPTOS, FUERZAS I VIOLENCIAS, I DE OTROS DELITOS CONTRA LAS BUENAS COSTUMBRES

Art. 561. El que para abusar de una persona, o para hacerle algún daño, la lleve contra su voluntad de una parte a otra, bien con violencia material, bien amenazándola, intimidándola de manera que le impida toda resistencia, bien tomando el carácter de autoridad lejítima o suponiendo una orden de ésta, sufrirá la pena de uno a cuatro años de prisión. Además, si llena el objeto de su engaño o causa y la persona violentada muere o sufre herida, maltratamiento de obra o cualquier otro daño, se le aplicarán las penas impuestas a dichos delitos.

Art. 562. El que con el mismo objeto i con cualquier otro engaño que el expresado en el artículo anterior, sin violencia ni amenaza, robe fraudulentamente a una persona que se deje llevar sin conocer el engaño, sufrirá por este solo engaño de seis meses a un año de prisión, sin perjuicio de la pena que merezca por el daño si ejecuta alguno contra la persona robada.

Art. 563. Si el reo en cualquiera de los casos de los dos artículos anteriores, abusare deshonestamente de la persona robada, contra la voluntad de ella, sufrirá además cuatro años de reclusión i terminada la pena será desterrado por un término de ocho a diez miriámetros del vecindario de persona violada.

Art. 564. Se considera comprendido en el caso del anterior artículo i se castigará según él, al que viole a una persona privándola previamente del uso de su razón, con licores fuertes u otras confecciones o medios que produzcan igual efecto, $i$ al que para el mismo fin se aprovecha de la ocasión de hallarse la persona ofendida privada del uso de la razón, por embriaguez, enfermedad o por cualquier otro accidente, sea o no provocado o procurado por el reo.

Art. 565. Si la persona robada en cualquiera de los casos de los artículos 561 i 562 no hubiere parecido al tiempo de terminarse el juicio, su 
desaparición será una presunción legal de asesinato, i se aplicará al reo la pena correspondiente a los asesinatos, si no justifica la existencia de la persona robada. ${ }^{4}$

Como podemos observar, para el legislador, en este caso en particular, lo que se entiende por delitos criminales sexuales está directamente vinculado con las denominadas "buenas costumbres", es decir, con la moral. En síntesis, este tipo de agresiones, los raptos, la fuerza y la violencia, están connotados, no como delitos contra la libertad sexual sino como delitos contra la moral social, como se puede observar en el artículo 563 que dice "Si el reo en cualquiera de los casos de los dos artículos anteriores, abusare deshonestamente de la persona robada, contra la voluntad de ella... $)^{5}$. En esta perspectiva lo que le interesa al legislador es la protección del bien denominado "buenas costumbres", por encima de los bienes de la libertad e integridad sexual del individuo.

Con la anterior representación, el Código Penal de 1890 promulgado bajo la llamada "Regeneración", agrupó los delitos sexuales bajo dos títulos: los delitos contra la moral pública (Título XVIII), que hacían parte del Libro Segundo que se ocupaba de los "delitos que afectan principalmente a la nación o a la sociedad o que sean cometidos por empleados públicos" y el Título Primero (delitos contra los particulares), en su Libro Tercero: contra las personas. Entre los delitos contra la moral pública se incluían los siguientes: de las palabras, acciones, escritos, pinturas y otras manufacturas obscenas, el abuso de otra persona del mismo sexo (relaciones homosexuales), la alcahuetería, la corrupción de jóvenes, el incesto y el amancebamiento público. Dentro de los delitos contra las personas se contemplaban el rapto, el adulterio, el estupro alevoso y la seducción. En síntesis, vale la pena resaltar, que en el Código Penal de 1890 se hace imposible, en materia sexual, hacer una distinción entre moral y derecho porque parte de una insoluble confusión entre delito y pecado. La moral cristiana que la inspiraba proclamaba un profundo repudio por el sexo no reproductivo, por los placeres "inútiles" y "estériles". Se confunde entonces pecado y vicio (Bernate, 2004: 543). Para esta moral, las conductas sexuales deben estar encaminadas a materializar la obra de Dios. La vida sexual, como se resaltó arriba, debe tener exclusivamente una función reproductiva y todo tipo de conducta sexual que no esté enmarcada en este sentido, será catalogada de inmoral (Tomás y Valiente, 1990:76). Entendiendo moral como el conjunto de valores y reglas de acción que se proponen a los individuos o a los grupos a través de aparatos prescriptivos como la familia, las instituciones educativas, y la iglesia, entre otros (Foucault, 2007:26).

${ }^{4}$ Biblioteca Bartolomé Calvo (BBC). Cartagena, Gaceta de Bolívar Trimestre LXIII. $\mathrm{N}^{\circ} 705$. Sábado 20 de agosto de 1870 . P. 320 a $327 . \mathrm{N}^{\circ} 709$. Lunes 5 de septiembre de 1870 . P. 353 359. N 711 Sábado 17 de septiembre de 1870. 369 a 375 . N ${ }^{\circ} 713$. BBC Gaceta de Bolívar. Martes 27 de Septiembre de 1870. Pp. 393 a 396.

${ }^{5}$ En la ley penal colombiana del siglo XIX, la palabra "torpe o deshonesta" permitía describir conductas que ban desde cantar o recitar "canciones torpes" hasta actos carnales, abusos deshonestos, cópula, violación, fuerzas y ultrajes, entre otras, que ofendían el pudor y las buenas costumbres. En os códigos penales colombianos de este periodo no aparece por ninguna parte la palabra sexual. 


\section{PRÁCTICA JUDICIAL}

\section{La práctica judicial condicionada por los prejuicios morales y religiosos.}

La práctica judicial en materia de delitos sexuales a finales del siglo XIX estaba caracterizada por una fuerte carga de prejuicios morales y religiosos. El orden moral y religioso se visualiza e interfiere permanentemente en los procesos judiciales relacionados con delitos sexuales, lo que los define por su carga de prejuicios en ese sentido. Los funcionarios se ocupan más por indagar por la conducta moral de la ofendida que por la ocurrencia de la conducta punible. Se preocupan más si es recurrente en la mujer ofendida las conductas que atenten contra el pudor y las buenas costumbres que por otra cosa, incorporando en sus informes judiciales juicios morales y religiosos, definiendo de alguna manera el resultado de los procesos. Blanca Melo al respecto plantea lo siguiente:

El estudio de expedientes judiciales acerca de delitos de fuerza y violencia, estupro y rapto en Antioquia entre los años 1890 y 1936, permite mostrar como la aplicación de la justicia está atravesada por convicciones morales y religiosas, por una imagen ideal del comportamiento de hombres y mujeres y sobre todo por el convencimiento de la culpabilidad de las mujeres. Cuando una mujer es víctima de alguno de estos delitos, jurídicamente es considerada como ofendida, pero casi siempre en la práctica judicial, se convierte en acusada; es así como, sin importar la edad ni las circunstancias del delito, los funcionarios indagan por su conducta, su vida, su moralidad, y sobre todo si es susceptible de sentir pasiones, condición que la hace sospechosa de haber incitado la comisión del delito. (op.cit.: 108)

Comprobar la conducta moral, el grado de educación y la posición social era fundamental para los jueces al momento de dar el veredicto y aplicar la pena. De alguna manera lo que se esperaba evidenciar era el comportamiento en sociedad de la mujer y cuál era su reputación a nivel social y con relación a esta información orientar el sentido del fallo. En este sentido, era fundamental para los jueces tratar de establecer si mantenía relaciones sexuales ilícitas, si era tímida, honesta y de buenas costumbres religiosas, para tomar una posición definitiva frente al proceso y en este sentido se diseñaban los cuestionarios que los testigos llamados a declarar debían responder (Gutiérrez, 2009: 174). 


\section{El peritazgo en los procesos por delitos sexuales}

En los procesos por delitos sexuales en el siglo XIX, los peritos tenían la función de demostrar hasta donde había sido producido el daño en el cuerpo de la víctima por parte del agresor, lo que implicaba realizar toda una exploración en el cuerpo de la mujer agredida, sobre todo en sus partes íntimas. Los reconocimientos realizados en los órganos sexuales de la mujer agredida consistían en verificar si hubo desfloración o no, cuando se trataba de la violación de una doncella. Estos peritazgos tradicionalmente los realizaban peritos legos sin diploma, como también algunas mujeres que cumplían en la comunidad la función de comadronas o parteras. Para el caso antioqueño a finales del siglo XIX el dictamen médico-legal rendido por médicos profesionales empezó a desplazar al dictamen rendido por peritos sin diploma. La importancia del dictamen médico-pericial fue determinante en las decisiones tomadas por los funcionarios judiciales en este tipo de proceso y se constituían en plena prueba para abrir la causa criminal, de acuerdo con la exigencia del artículo 1627 del Código Judicial:

Luego que el Juez competente haya concluido o recibido las diligencias correspondientes para comprobar el cuerpo del delito y descubrir los culpables, examinará si la averiguación está perfecta [...] pero si no lo estuviere, dispondrá lo conveniente a la perfección del sumario. Si encontrare que hay plena prueba de la existencia del delito, y por lo menos un testigo idóneo o graves indicios contra alguno o algunos, declarará que hay lugar al seguimiento de causa contra éstos $[\ldots]^{6}$

El informe de los peritos incluía el examen del entorno o del espacio donde sucedieron los hechos, la idea era encontrar rastros que permitieran aseverar que si hubo una agresión sexual que se constituyera como delito, pero realmente el peritazgo se centraba era en el cuerpo de la mujer ofendida, especialmente en sus órganos genitales:

No se comprobó el cuerpo del delito de fuerza y violencia: no hallaron los peritos en el cuerpo de la sedicente ofendida ni el más leve rastro de maltratamiento de obra [...] por otra parte, los indicios que recaen sobre [F.B.] como autor del delito son en extremo débiles... ${ }^{7}$

Leoncio Barreto plantea, con relación a los vestigios que pueda dejar una violación, que se debe tener en cuenta que esta se puede dar desde en una

6 Del Valle Montoya, Piedad. "El dictamen médico-legal en Antioquia: 1887-1930". Todos somos historia. Sexta Todos somos historia. Sexta
parte. Documento de internet. Www.canalu.com.co tsh/m21 gallery/2553. Bajado $1^{\circ}$ de octubre de 2011. 6:34. P.M. P. 343.

${ }^{7}$ Archivo Histórico Judicial de Medellín (A.H.J.M.). Medellín. Caja 98, doc. 2212 f. 35r. 
niña virgen hasta en una mujer ramera, pues sólo se requiere que el acto se haya realizado sin la voluntad de la mujer, y concluye:

Si esta condición ha existido, naturalmente habrá habido lucha y los rastros de ésta en los esfuerzos para defenderse y en la violencia ejercida para sujetarla, se encontrarán en el lugar donde se efectuó el acto, en los vestidos y el cuerpo de la mujer y aun del hombre. Así se hallarán siempre desgarramientos, equimosis, manchas de esperma, de licor vajinal y aun pelos que pueden ser analizados: además de los caracteres que puedan encontrarse en la vulba [sic] y la vagina. (1890: 32)

Es claro para Barreto que el consentimiento es la clave para tipificar el delito de fuerza y violencia en una agresión sexual contra una mujer y en este sentido el médico legista debía demostrar, a través de rastros o huellas dejadas en el cuerpo de la mujer o en el lugar de los hechos, el grado de violencia utilizado que nos permitan conjeturar la ausencia de consentimiento. Igualmente en su Tratado de Medicina Legal de 1896 Carlos Putnam se pronuncia claramente, con relación al tema del consentimiento de la víctima en delitos de fuerza y violencia, afirmando que:

Cuando la desfloración recae en una mujer menor de doce años, aunque no se emplee la fuerza, ni haya privación de razón ni de sentidos, aunque sea con el beneplácito de la niña, el hecho se califica de violación por considerar á aquella incapaz de consentir [...] (op.cit.:339)

Para el caso de Santander a finales del siglo XIX, María del Rosario Romero plantea que las mismas mujeres que son llamadas como examinadoras o peritas para dictaminar sobre la violación, siguen al pie de la letra el objetivo señalado en las preguntas que envía el juez: "¿Hay desfloramiento de los órganos genitales?, ¿Se le ha alcanzado a romper el órgano respectivo?". Y afirma al respecto que "en una sociedad himenolátrica, por supuesto, no interesa la persona sino la dimensión de la abertura de una sutil membrana localizada en el introito de la vagina. Los sentimientos, la humillación, el maltrato físico no importan". Y en un proceso específico contra una niña llamada Micaela, concluye que "los examinadores, que despatarraron otra vez a Micaela, enunciaron: "si le fue introducido el miembro de algún hombre en la vulva fue en mui poca cantidad, es decir, la punta de tal miembro." (op.cit.: 32). 


\section{Características del proceso judicial por delitos sexuales}

Con relación al tratamiento procesal de los delitos sexuales en otros países de América Latina, como por ejemplo para el caso de Argentina a finales del siglo XIX, se limitó la acción del Estado en estos delitos porque la ley determinaba que sólo podía iniciarse la acción penal por acusación o a instancia de la interesada, a excepción de un impúber que no tuviera padres ni guardadores, en tal caso podía acusar cualquier persona (Sedeillán, 2009:114). Esto respondía al derecho que la ley le concedía a la víctima para proteger su intimidad. Igualmente los jueces argentinos consideraron que la denuncia no era suficiente para impulsar de oficio el proceso judicial sino que se requería de una participación más activa de la víctima para que el imputado pudiera ser penalizado (Ibíd.: 105). En cambio para el caso colombiano, determinar el estado civil de la víctima era fundamental para iniciar el proceso, saber si la víctima era casada, soltera o viuda, y sobre todo saber cuál era su reputación, le proporcionaba a los funcionarios judiciales la idea del sentido que debía asumir la investigación, es decir, en este caso la vida privada de la víctima se exteriorizaba, se colocaba en la palestra pública sin ninguna consideración para poder poner en marcha la acción penal del Estado (Gutiérrez, op.cit.:175).

Con relación al impulso del proceso judicial en Colombia por delitos sexuales, Natalia Gutiérrez argumenta que eran los testigos con sus testimonios los máximos dinamizadores de la investigación judicial, constituyéndose el chisme en el más importante factor dentro del proceso. Los testigos afirmaban si conocían o no a los sujetos procesales, opinaba sobre cuál era la conducta moral de la víctima, que habían escuchado decir de ella, cuál era su posición social y grado de educación. En este sentido el "rumor público" o chisme se constituyó como el máximo dispositivo de control social haciendo voz pública la vida privada de las personas (Ibíd.: 164). Pero el mayor obstáculo en materia procesal para llegar a la posibilidad del castigo para los responsables de estos delitos era la precaria carga probatoria y entonces el principio del derecho penal denominado el in dubio pro reo, la duda favorece al reo, implicaba que los imputados terminaran en su mayoría siendo sobreseídos por falta de pruebas. El acervo probatorio se construyó por medio de estrategias como el informe de peritos, los testimonios, la declaración juramentada, la indagación de los implicados y la inspección judicial, que finalmente terminaban siendo debilitados por una mentalidad moralista que hicieron que el chisme desplazara axiológicamente los demás elementos de prueba, que finalmente favorecían a los victimarios promoviendo la impunidad en la comisión de este tipo de delitos (Del valle, 2010: 227). 


\section{Casos de delitos sexuales a finales del siglo XIX en Colombia}

\section{Tres casos de agresiones sexuales en Antioquia}

En el año de 1893 en el municipio de Sonsón, María del Carmen Buitrago de 12 años rinde declaración sobre una agresión sexual por parte del presbítero Ramón Hoyos, que amparado en su condición de eclesiástico, abusa de ella. Veamos el relato de la niña:

$Y$ allí me preguntaba si yo iría a ser hermana de la caridad o monja o si me gustaba el matrimonio, a lo cual le dije que me gustaba más lo último, es decir casarme. Que en seguida, y después de que él ya había cerrado la puerta con llave, me cogió, me sentó encima de sus rodillas, y levantándome la ropa me tocaba por todas partes, pellizcándome; me manifestaba que 'él me iba a dar la vocación y yo estaba en el convencimiento de que nada malo me haría, también me metía la lengua en la boca y me decía que era para darme la vocación. En seguida me cogió, me subió a una cama, me alzó la ropa... puesta la sotana se me subía... se me arrimaba muy duro... me dolió mucho, y también veía que se limpiaba... ${ }^{8}$

En el año 1894, con relación a una agresión sexual de la que fue víctima en un espacio rural de Antioquia, la niña María de las Mercedes Barrientos de 12 años, declaraba ante el juez:

Me dijo así es como se coge frisol y me derribó y me metió esa cosa por dentro... Me metió ese chi... (ilegible) al orinador por donde yo orino, y aunque yo gritaba muy recio no me largaba y mucho rato después me largó. Al día siguiente vi que yo hechaba postema por donde orino y los trapos muy sucios y me estuve tres días con dolores y de allí para acá siempre los siento pero no son recios sino de la tarde para adelante y cuando voy a orinar. Guillermo no me dejaba pasar, y aunque yo lo tumbaba, él se me volvía a montar...9

Igualmente la niña Carmen Rosa de 11 años dice haber sido violada por un tendero en el municipio de Rionegro, declarando ante el juez que:

8 AHJM. Caja 102, doc. 2228, f $7 \mathrm{r}$ y $7 \mathrm{v}$.

9 AHJM. Caja 101, doc. 2217, f 2r. 10 AHJM. Caja 430, doc.
9564, f 2 r.
Me cogió, me acostó, me alzó la ropa y me introdujo entre las piernas, una cosa dura y gruesa que no sé cómo se llama. Cuando yo gritaba, se me quitaba de encima, pero luego que me callaba, se me volvía a montar, hasta que como dije antes, me introdujo por entre las piernas una cosa que no $\operatorname{conozco}{ }^{10}$. 


\section{Dos casos de agresiones sexuales en Santander}

En el año de 1886 en Umpalá Santander, un agricultor cincuentón de nombre Julián Bustos agredió sexualmente a una niña de ocho años llamada Micaela Chanagá enviada a su finca por yucas y plátanos. Declarándose buen cristiano, cumplidor del diezmo y trabajador. Esta condición no impidió que se aprovechara de la niña y la llevara en vilo hasta su camastro de cuero para violarla produciéndole un grave daño físico, pues la descaderó y la dejó sin poder caminar. Después fue sobreseído, al declarar ante el tribunal en San Gil y luego en Bucaramanga, que "todos los días la mandaban los taitas a mi casa... bien pueden ustedes considerara aquella tentación", Además "fue con voluntad de ella" (Romero, op.cit: 30).

En 1881 el alcalde Girón de nombre Manuel Arenas, comerciante de treinta años, casado, conocido con el alias de "ruyas", se embriagó un viernes en la tarde y salió a buscar aventuras al pueblo:

El varón es de la calle, la mujer es de la casa reza el antiguo dicho popular, por eso Eudocia, la modista de veintiún años y Bibiana, la tendera de veinticinco, se habían recogido temprano y dormían cuando a eso de la once de la noche, oyeron el escándalo de golpes sobre la puerta; era el señor alcalde quien amenazaba tumbar ésta a patadas y disparar su arma sino le dejaban pasar. Las mujeres asustadas quitaron la tranca y abrieron su tienda, quizás pensando en distraerlo ofreciéndole un guarapo. Pero él venía violento, fue más allá del mostrador, empujó a Bibiana cuando ésta trató de obstaculizarle el paso y se ensañó con Eudocia encerrándola y violentándola sobre la tierra del patio unas seis veces seguidas. Bibiana y una anciana que vivía con ellas, no pudieron defenderla; sólo escucharon sus gritos pidiendo auxilio y sus inútiles forcejeos frente a la fuerza muscular de Manuel. (Ibíd.: 33).

\section{Informes de autoridades del Estado Soberano de Bolívar sobre delitos sexuales}

En informe del Procurador General del Estado Soberano de Bolívar en el año de 1878, con relación al tema de la administración de justicia, rinde el siguiente balance criminal donde aparece el índice de la comisión de delitos sexuales:

Según datos suministrados por los Señores Fiscales de acuerdo con la disposición del artículo 28 de Código de Procedimiento en Negocios 
${ }^{11}$ Archivo Histórico de Cartagena (AHC). Cartagena,
Diario de Bolívar, 22 de agosto de 1878. La negrilla es nuestra.

12 AHC. Diario de Bolívar, 22 de agosto de 1878. La negrilla es nuestra.

${ }_{13}$ AHC. Diario de Bolívar, Cartagena, 2 de septiembre de 1879. La negrilla es nuestra.

${ }^{14}$ AHC. Diario de Bolívar, Cartagena, 7 de agosto de 1880. La negrilla es nuestra.

${ }^{15}$ AHC. Diario de Bolívar, Cartagena, 29 de agosto de 1881.
Criminales, los sumarios iniciados en el Estado, de 1. ${ }^{\circ}$ de Enero a 30 de Junio del año en curso asciende a 177 sin computar los iniciados en la provincia de Lorica, por no haber recibido aviso del caso. Las causas de la iniciación son las siguientes:

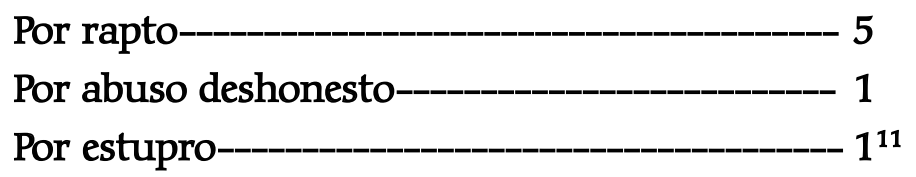

Continúa en su informe el Procurador General del Estado Soberano de Bolívar, con relación al tema de los negocios criminales y los delitos sexuales:

Se hace notar tambien, que los datos suministrados, en los negocios de que vengo hablando, por los señores Fiscales del Carmen, Monpos i Sincelejo no comprende, como los de las otras provincias, hasta el 30 de Junio, sino hasta el 30 de Abril. A cuarenta i dos llega el nùmero de dichas causas, las que fueron seguidas por los siguientes delitos:

$\begin{array}{ll}\text { Por estrupo - } & 2 \\ \text { Por seduccion i rapto-_-_ } & 1 \\ \text { Por abuso deshonesto-_-_ } & 1\end{array}$

Los Fiscales de la provincias del Carmen, Cartagena, Lorica, Magangué, Mompos, Sabanalarga i Sincelejo, han suministrado los datos que le correspondian, i de ellos resulta ser 116 el nùmero de las causas criminales pendientes; hacièndose notar que los Fiscales del Càrmen, Mompos i Sincelejo no se estienden mas que al 1er. Cuatrimestre. Los motivos porque esas causas se han iniciados son los siguientes:

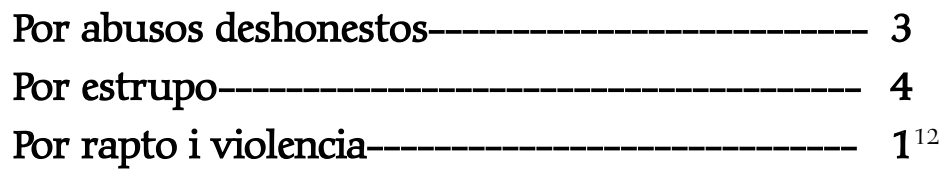

En informe del Gobernador de la provincia de Cartagena en el año de 1879, con relación al tema de la administración de justicia y los delitos sexuales, plantea lo siguiente:

El $1^{\circ}$ de julio había en la casa de prisión i reclusión 63 reos, han entrado hasta el 30 de junio último 22, han salido por haber cumplido la condena, por haberse rebajado el tiempo que le faltaba para cumplirla, i por haber muerto 9. Quedan 76 que son los que aparecen en la relación que acompaño: de este número 44 son reos de asesinato y homicidio, 13 de heridas, 3 de robo, 3 de hurto, 2 de parricidio, 5 de estupro, 1 
de estupro con violencia y asesinato, 3 de abuso deshonesto, 1 de prostitución de una hija menor $i 1$ de incendio. La edad del mayor número de condenados no excede de 40 años, hai 7 que pasan de ahí, uno de 70 y otro de 80 años. ${ }^{13}$

En el año de 1880 el Gobernador de la provincia del Carmen, con relación al tema de la administración de justicia donde aparecen registrados los delitos sexuales, informa lo siguiente:

Según las relaciones de causa que tengo a la vista, del $1^{\circ}$ de julio de 1879 al 30 de junio del presente año, han entrado en el Juzgado 58 sumarios por los siguientes delitos: Hurto, 15. Robo, 2. Heridas, 18. Rapto, 2. Seducción, 1. Incendio, 2. Maltrato, 4. Uso propiedad ajena, 2. Resistencia a mano armada a la autoridad, 1. Ultraje a la autoridad, 1. Fuerza i violencia, 1. Daños, 1. Falsedad, 1. Fuga, 1. Motín, 1. Sustracción de documentos públicos, 1. Extravío de un archivo público, 1. Adulterio, 1. Varios, 1. Omisión de cumplimiento de deberes legales, 1. En esos 58 aparecen 103 responsables, i se ignora todavía quien sea el autor de una falsedad i culpable del extravío de un archivo público. ${ }^{14}$

En el año de 1881 el Gobernador de la provincia de Magangué, rinde informe sobre el tema de la administración de justicia y los delitos sexuales:

SUMARIOS INICIADOS O RECIBIDOS: Por hurto, 12. Por heridas, 9. Por robo, 4. Por tentativa de homicidio, 3. Por resistencia a la autoridad, 2. Por omisión en el cumplimiento de sus deberes, 2. Por tentativa de hurto, 2. Por estupro, 1. Por id. de homicidio i hurto, 1. Por abuso deshonesto, 1. Por id. Id. Con violencia, 1. Por abuso de confianza, 1. Por tentativa de robo, 1. Por irrespeto a la autoridad, 1. Por alteración de documentos públicos, 1. Por maltrato, 1. Por infracción al artículo 229 del Código penal. Por infracción al artículo 415 del Código penal de la Nación, $1 .{ }^{15}$

Como se puede observar en estos informes los procesos abiertos por la comisión de delitos sexuales no eran pocos y eran igualmente constantes, lo que nos permite afirmar que su práctica era recurrente en el panorama de la vida social y cultural de los bolivarenses de este período. Prácticas que estaban enmarcadas dentro de toda una cultura de la trasgresión generalizada y estimulada por 
un Estado débil que se perfiló como incapaz de castigar verdaderamente a aquellos que se atrevieron a quebrantar su ordenamiento jurídico.

\section{CONSIDERACIONES FINALES}

La sexualidad es una invención socio-cultural construida a partir de la diferenciación biológica o sexual y está estructurada por cuatro componentes básicos: reproductividad, género, erotismo y afectividad (Foucault, 2005: 165). Con relación al género, este es el sexo socialmente construido. Lo que implica que los patrones de masculinidad y feminidad se modelan históricamente y se estructuran según los intereses de la época, entonces entendemos el constructo sexo-género como el conjunto de prácticas, símbolos, representaciones, normas y valores sociales que las sociedades elaboran a partir de la diferencia sexual anatómico-fisiológica y que dan sentido a la satisfacción de los impulsos sexuales, a la reproducción de la especie humana y en general la relación con las personas.

La sexualidad permite la instauración de la desigualdad entre los sexos, convirtiendo al género en el campo primario dentro del cual y por medio del cual se articula el poder y se convierte en una categoría persistente y recurrente que permite entender las demás desigualdades sociales. Entonces, el género es el paradigma del principio de desigualdad, que orienta su discurrir socio-sexual por una serie de creencias e ideas, principios y costumbres que dan sentido a sistemas patriarcales, orientados a su vez por la relación macho-hembra, que se exteriorizan en conductas de persecución, acoso, abuso, discriminación y resistencias entre un grupo sexual y otro, determinando y dando forma a un tipo de moral que no sería más que el espectro donde se reflejan las márgenes de variación o de trasgresión en relación con un determinado sistema prescriptivo en el campo de las conductas sexuales de una sociedad.

En el siglo XIX colombiano para la ideología cristiana predominante, la mujer es causa del mal, por lo que hay que alejarse de ella o domeñarla o castigarla. Tradicionalmente la doctrina cristiana abunda en ataques contra el sexo y la lujuria e igualmente en prevenciones contra la mujer. El discurso eclesiástico ha promovido el "debido uso" de la sexualidad, a la vez que ha recomendado una serie de disposiciones, mecanismos y condicionamientos como el matrimonio; simultáneamente ha sido claro en términos de prohibiciones para controlar y regular su práctica, en un verdadero ejercicio de poder sobre los sentidos y el cuerpo, que define una moral y una sexualidad especificas. Desde esta perspectiva, la doctrina cristiana recurrentemente y a través de 
sus teólogos señalaron a la mujer, como la principal incitadora del pecado en el hombre. Fundamentados en este enfoque, todas las mujeres serían por principio sospechosas, sea cual fuere la conducta del hombre frente a ellas, de provocadoras sexuales y por consiguiente responsables de dichas conductas, quedando el hombre libre de responsabilidad. Las mujeres víctimas de ataques sexuales, que se atrevieron a denunciar a sus victimarios y llevarlos ante las jueces, fueron tratadas con desdén y siempre miradas como sospechosas de mentir y sus declaraciones tomadas con desconfianza por las autoridades judiciales, ya que existía la creencia de que las ofendidas solían inculpar a otro para salvar al verdadero responsable.

En los diferentes casos relacionados con delitos sexuales, el vecindario veía culpable a las mujeres, pues suponía siempre que era por su culpa que ocurrían esos delitos, ya fuera porque los provocaran por incitación o por el mal cumplimiento de sus obligaciones, situación que según la mentalidad de la época, suscitaba estos hechos. Así, el juego de culpar a la víctima, cuando el delito tiene que ver con las relaciones sexuales o con la agresión sexual de un hombre a una mujer, es usado como mecanismo de disculpa, soportado en un medio social ideológicamente discriminatorio por género. Es así como en el curso de los procesos, la intervención de los vecinos con sus testimonios y comentarios, inmersos en una mentalidad patriarcal propia de una sociedad donde el chisme funcionaba como mecanismo de control social, terminaban dándole la razón al agresor y responsabilizando a la víctima de la agresión, situación que agravada por el sexismo de la legislación, permitía que el delito quedara en la impunidad. En este sentido, el temor al "qué dirán" estuvo íntimamente ligado al "rumor público", se evitaba el primero para que no se desatara el segundo, entonces las mujeres evitaban al máximo estar en boca de todo el mundo, buscando a toda costa preservar la imagen de mujer honorable y alejarse como fuera del escándalo y el veto social, situación que posibilitaba y promovía la impunidad frente a la comisión de este tipo de delitos.

El ideal de mujer de la época es el de aquella que está confinada en su casa, dedicada a las labores domésticas y si tenía pretendientes debía recibirlos en presencia de sus padres, sin nada de fiestas y, como decía un testigo en uno de estos procesos, la mujer debe estar "de la cama al fogón y del fogón a la cama". De lo contrario toda conducta era sospechosa y ponía en riesgo su honra y el honor de su virginidad, "joya la más querida de la mujer y las más protegida de la sociedad". Es así como, los informes de los funcionarios judiciales están cargados de prejuicios morales y religiosos que de alguna 
manera alteran el procedimiento judicial e impiden encontrar la verdad y castigar a los responsables. Entonces el proceder judicial se ve interferido por convicciones morales y religiosos, por una imagen ideal del comportamiento de hombres y mujeres, y sobre todo por el convencimiento de la culpabilidad de las mujeres, que jurídicamente son consideradas como ofendidas, pero casi siempre, en la práctica judicial, se convierten en acusadas. Comprobar la conducta moral, el grado de educación y la posición social era fundamental para los jueces al momento de dar el veredicto y aplicar la pena.

\section{Fuentes y bibliografía}

\section{Archivos}

\section{Archivo Histórico Judicial de Medellín (AHJM).}

Caja 98, doc. 2212, f.35r.

Caja 102, doc. 2228, f7r y 7v.

Caja 101, doc. 2217, f2r.

Caja 430, doc. 9564, f2r.

\section{Archivo Histórico de Cartagena (AHC)}

Diario de Bolívar, 22 de agosto de 1878.

Diario de Bolívar, 22 de agosto de 1878.

Diario de Bolívar, Cartagena, 2 de septiembre de 1879.

Diario de Bolívar, Cartagena, 7 de agosto de 1880.

Diario de Bolívar, Cartagena, 29 de agosto de 1881.

\section{Biblioteca Bartolomé Calvo de Cartagena (BBC)}

Gaceta de Bolívar $\mathrm{N}^{\circ}$ 705. Sábado 20 de agosto de 1870 . P. 320 a $327 . \mathrm{N}^{\circ}$ 709. Lunes 5 de septiembre de 1870. P. 353 a 359. N 711. Sábado 17 de septiembre de 1870. P. 369 a 375. No 713. BBC. Gaceta de Bolívar. Martes 27 de Septiembre de 1870. Pp. 393 a 396.

Código de Procedimiento en los Negocios Criminales del Estado Soberano de Bolívar. Edición Oficial. Bogotá. Imprenta de Medardo Rivas. 1876.

Documento de internet. Www.canalu.com.co/tsh/m21_gallery/2553. Bajado $1^{\circ}$ de Octubre de 2011. 6:34. P.M. P. 343.

Sentencia 18455 de septiembre 7 de 2005-Corte Suprema de Justicia-Sala de Casación Penal. Colombia. 


\section{BIBLIOGRAFIA}

Barreto, Leoncio. Prontuario de medicina legal y jurisprudencia médica. Imprenta "La Comercial". Bogotá. 1890 .

Bernate Ochoa, Francisco. "El Código Penal colombiano de 1890". Revista Estudios Socio-Juridicos. Nº02. Julio-Dic. 2004. Pp. 537-558.

Bidegain, Ana María. "Control sexual y catolicismo". Las mujeres en la historia de Colombia. Tomo II, Mujeres y sociedad. Editorial Norma. Bogotá. 1995.

Bohórquez, Luís y Bohórquez, Jorge. Diccionario jurídico colombiano. Editora Jurídica Nacional. Bogotá. 2006.

Del Valle Montoya, Piedad. "Aborto y delitos sexuales en Antioquia a finales del siglo XIX y principios del siglo XX: una historia secreta." Revista Estudios de Derecho. $\mathrm{N}^{\circ} 149$. Universidad de Antioquia. Junio de 2010. P. 219-242.

Foucault, Michel. Historia de la sexualidad 1. La voluntad de saber. Madrid: Siglo XXI. 2005.

Historia de la sexualidad 2. El uso de los placeres. México: Siglo XXI, 2007.

Gutiérrez Urquijo, Natalia María. "Los delitos de aborto e infanticidio en Antioquia: 1890-1930". Historia y Sociedad. N 17 . Universidad Nacional de Colombia. Medellín. 2009. Pp. 159-177.

Martínez, Rosario. "Delitos contra la libertad sexual desde la perspectiva de género". Anuario de Derecho Penal. $\mathrm{N}^{\circ}$ 19. 2000. Madrid. Pp. 78-93.

Malagón Pinzón, Jenny Margarita. Escenas de pecado y delito. Relaciones incestuosas en la Nueva Granada (1648-1833). La Carreta Editores. Medellín. 2011.

Melo, Blanca Judith. "Primero muertas que deshonradas. Antioquia: 1890-1936". Historia y Sociedad. №6. Universidad Nacional de Colombia. Medellín. Dic. 1999. Pp. 108-125.

Putnam, Carlos E. Tratado práctico de medicina legal en relación con la legislación penal y Procedimental del país. Imprenta de Antonio M. Silvestre. Bogotá. 1896.

Rodríguez Piñeres, Eduardo. Constitución y códigos de Colombia. Librería Americana. Bogotá. 1927.

Palobra No. 13. Agosto de 2013 
Romero Contreras, María. Amor y sexualidad en Santander. Siglo XIX. UIS. Bucaramanga. 1998.

Sedeillán, Gisela.. "Los delitos sexuales: la ley y la práctica judicial en la provincia de Buenos Aires durante el periodo de codificación del derecho penal argentino: 1877-1892". Historia Crítica. N ${ }^{\circ}$ 37. Bogotá. Abril 2009. Pp. 100-119

Tomás y Valiente, Francisco. Sexo barroco y otras trasgresiones premodernas. Alianza. Madrid. Alianza. 1990. 


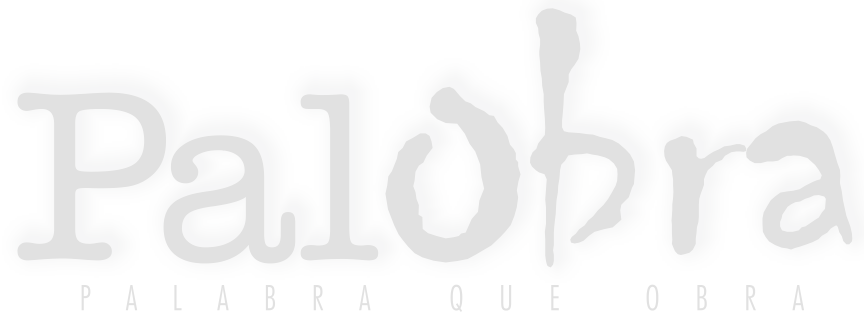

